\title{
Editorial
}

\section{El 150 aniversario del Manifiesto del Partido Comunista}

A mediados de febrero de 1848 , hace 150 años, un nuevo panfleto comunista se imprimio en la pequeña imprenta de Bishopsgate en Londres. Estaba escrito en alemán y se titulaba Manifest der Kommunistischen Partei. Varias copias se distribuyeron en los principales países de Europa. Hasta ese momento, las principales ciudades del continente habían sido testigos de numerosas revueltas obreras y disturbios callejeros. Los pequeños núcleos de activistas revolucionarios estaban esperando una vigorosa declaración de sus principios, que les permitiera guiar su trabajo y orientar a las masas hacia su incorporación en el movimiento revolucionario.

Las primeras líneas del panfleto expresaban un desaffo para las fuerzas progresistas y revolucionarias: "Un fantasma recorre Europa: el fantasma del comunismo. Todas las fuerzas de la Vieja Europa se han unido en santa cruzada para acosar ese fantasma (...) ha llegado el momento de que los comunistas expongan a la faz del mundo entero sus conceptos, sus fines y sus aspiraciones; que opongan a la leyenda del fantasma del comunismo un manifiesto del propio Partido".

El panfleto se tradujo rápidamente a varias lenguas. En inglés se conoció como Communist Manifesto. En la primera versión inglesa, publicada en 1850, los autores del panfleto, que hasta ese momento eran desconocidos, fueron revelados por vez primera: Karl Marx y Frederick Engels. Desde entonces, el Manifiesto Comunista se considera como el documento fundador del movimiento comunista en el ámbito mundial y del internacionalismo socialista obrero. ¿Qué validez tiene el Manifiesto 150 años después de su publicación? 
El perfodo histórico comprendido entre 1840 y 1850 fue un momento de despegue del capitalismo industrial y nacional. Una creciente ola de revoluciones nacionales, burguesas y liberales sacudieron Europa en 1848; y la revolución industrial se celebró en la Gran Exposición de Londres en 1851.

En la época actual se observa el despegue y la extensión del capitalismo informatizado y globalizado. Esta globalización se manifiesta en la ampliación y profundización, a escala mundial, de las relaciones capitalistas en todos los ámbitos de la vida económica, social, política y cultural, asf como por la desaparición de cualquier modelo alternativo al capitalismo. La informatización se observa en la producción y la utilización masiva de bienes y servicios computarizados, y en la creciente sustitución de la organización por la red electrónica como forma de relación del capitalismo central.

Aparentemente, el Manifiesto Comunista de 1848 no tiene mucho que decir en relación con los nuevos fenómenos del capitalismo de nuestra época. Sin embargo, La Ideología Alemana de 1845-6 contiene un texto clave para ello. Los dos textos son complementarios en varios sentidos. El primero es filos6rico, el segundo es político. El primero aborda el comunismo primariamente como una transformación histórica y como un movimiento social; el segundo como un programa y una organización políticos. El primero puede ser considerado como reflexivo y teórico, el otro como persuasivo y utópico. Ambos combinan elementos analíticos-racionales y utópico-proféticos, una combinación ciertamente esencial para cualquier doctrina social emancipatoria. Ambos documentos son significativos en varios sentidos y tienen potencialidad para iluminar, 150 años despues, los procesos actuales del capitalismo y los caminos sobre su posible superacion.

El texto relevante de la Ideología Alemana es el siguiente:

"Esta 《<alienación〉> - para hacernos entender por los filósofos- no puede ser naturalmente abolida, sino es con dos condiciones prócticas. Para que se convierta en una fuerza <<insoportable〉>, es decir, en un poder capaz de provocar una revolución es necesario que haya hecho de la masa humana un conglomerado totalmente <<privado de propiedad>> y que al mismo tiempo se encuentre en contradicción con un mundo de riqueza y una cultura auténtica, lo que presupone en ambos casos un gran crecimiento de la fuerza productiva, es decir, un punto elevado de su desarrollo. Por otra parte, este desarrollo de las fuerzas productivas (que ya implica el desarrollo de la existencia empírica de los hombres en el nivel de la historia mundial y no en el nivel local) es una condición práctica y previa, absolutamente indispensable, ya que sin ello sería la penuria la que se tornaría general y con la necesidad se recomenzaría la lucha por lo indispensable, y volveríamos a caer en el antiguo pantano y además, porque sólo este desarrollo universal de las fuerzas productivas es también una condición sine qua non que hace posible el 
establecimiento de relaciones universales del género humano y que por una parte engendra el fenómeno de la masa <<privada de propiedad > simultáneamente en todos los países (concurrencia universal) convirtiendo a cada uno de ellos en dependientes de las conmociones de los otros, integrando, finalmente, a los hombres que viven empíricamente la historia mundial en lugar de los individuos que viven a un nivel local. Sin todo esto, resultaría, en primer lugar, que el comunismo sólo podría existir como un fenómeno local; en segundo lugar, que las fuerzas de las relaciones humanas en sí mismas no habrían podido desartollarse como fuerzas universales y por tanto insoportables, quedando como "circunstancias" provocadoras de supersticiones locales; y en tercer lugar, toda ampliación de los intercambios aboliría el comunismo local".

El comunismo, empíricamente, sólo es posible como acto "repentino" y simultáneo de los pueblos dominantes, lo cual presupone el desarrollo universal de la fuerza productiva y los intercambios mundiales estrechamente ligados al comunismo (...). El comunismo no es para nosotros, ni un estado que sea necesario crear, ni un ideal sobre el cual haya de reglamentarse la realidad. Nosotros Ilamamos comunismo al movimiento real que anula el estado actual. Las condiciones de este movimiento son resultantes de premisas actualmente existentes".

Podemos identificar cinco puntos importantes en el texto:

(a) El carácter mundial de las condiciones para superar la alienación. La contradicción entre la gran masa de la humanidad sin propiedad y el "mundo de riqueza y cultura auténtica" se ha ido incrementando desde los tiempos de Marx. En nuestros días se observa la profundización de las contradicciones entre los mundos de riqueza y cultura y los países pobres, entre el norte y el sur, entre el occidente y el resto.

Para Marx, la resolución de esta contradicción requiere de un desarrollo tal de las fuerzas productivas y de la riqueza que permita superar la necesidad, la penuria y la lucha por la salisfacción de las necesidades básicas. La revolución tecnológica basada en la informática, que en la actualidad se está desarrollando en los países capitalistas industrializados, posee la potencialidad de asegurar un aumento de la productividad y del pleno empleo con una disminución del tiempo de trabajo (en los países centrales de un promedio de 1600 a 1000 horas por año en los próximos 15-20 años). Sin embargo, este desarrollo está ampliando la fragmentación y estratificación de la sociedad, más que fomentando vínculos de carácter universal entre los individuos y los grupos sociales.

Las dos condiciones claves para superar la alienación que Marx establece, la "existencia empírica de los hombres en el nivel de la historia mundial y no en el nivel local" y "el establecimiento de relaciones universales del género humano" que convierte a cada país "en dependiente de las conmociones (revoluciones) de 
los otros", no se han logrado concretar todavía. A pesar del incremento de la pobreza y de la desigualdad y del surgimiento de movimientos sociales antisistémicos, con orientación global, no existe todavía una "masa homogénea empobrecida". vinculada por relaciones universales, capaz de luchar unitariamente en un plano global para superar las condiciones que generan la alienación.

(b) El proletariado y el comunismo como existentes únicamente en el ámbiso mundial. En este siglo, de lo que hemos sido testigos es de la existencia de movimientos proletarios de carácter nacional y de sistemas comunistas nacionales, Ja mayoría de los cuales o se han extinguido o se encuentran en una posición precaria y a la defensiva.

La aspiración de Marx de superar la alienación humana a través de una revolución proletaria de carácter mundial hay que historizarla y asumirla en forma figurativa, más que literal. En este sentido, si tomamos el término "proletario" como una metáfora que designe a lodos los sectores oprimidos y alienados, a todos los individuos y grupos a lo que les son negados sus derechos, el despliegue de sus capacidades y su potencial para realizarse como personas, podemos tener una mejor perspectiva para imaginar el cambio social en la actual situación mundial. Desde este punto de vista. se podrían encontrar evidencias empíricas y argumentos para justificar una praxis de movimientos sociales para superar la alienación a nivel mundial. Que la superación de la alienación es inconcebible en el puro ámbito nacional quedó demostrado por el colapso del socialismo real, no sólo en un país sino también en un bloque de países. Además, la creciente interdependencia implica que no podemos construir el socialismo en la actualidad, o preservar incluso un estado de bienestar capitalista, en un solo país.

(c) El comunismo como el verdadero movimiento social. El comunismo ha sido, primariamente, un asunto de estados comunistas y de estados socialistas estatistas. También ha sido un ideal al que la realidad debe ajustarse, un ideal que ha estado únicamente en la cabeza de los intelectuales socialistas. Si el comunismo está llamado a ser un movimiento real que "anula el estado actual" de cosas, entonces requiere que se oriente hacia los nuevos movimientos reales de la sociedad que en el presente pretenden transformar el orden internacional. Esto no debe implicar entrar en contradicción con el clásico movimiento obrero y sindical. Entre los nuevos movimientos sociales orientados a la transformación global debe existir un nuevo movimiento social sindical que explícita o implícilamente supere el economicismo, el reformismo o el activismo insurreccional de sus predecesores.

(d) La necesidad de una revolución simultánea en los paises dominantes. Esta afirmación de Marx revela su eurocentrismo y su visión apocalíptica de la revolución proletaria. Esto no fue superado por el concepto de Lenin sobre el "eslabón débil" ni por el desarrollo combinado y desigual de Trotsky. Lo que 
ellos entendieron, porque eșa era la experiencia de Rusia, es que cl desartollo mundial de las relaciones capitalistas de producción es multifacético y desigual en esencia. Pero esto no implica, como sí lo fue en parte en Lenin y sus seguidores, que podamos darle primacía revolucionaria a los países atrasados sobre los desarrollados, o trasladar el protagonisıno revolucionario del proletariado anticapitalista de los centros industrializados a las masas antiimperialistas de la periferia rural. Más bien debe persuadịnos a abandonar cualquier idea de países o bloques de ellos o partidos que "puedan ser o representar modelos de desarrollo cultural e industrial, o constituirse en vanguardias revolucionarias.

Asumiendo la especilicidad de cada país en el marco de la globalización capitalista se requiere: (1) identificar estructuras, procesos y experiencias similares, en diferentes países, que posibiliten un acción global común; (2) reconocer que la posición y experiencia diferencial de cada país en el aclual orden capitalista mundial implica distintas acciones prioritarias, descubrimientos, invenciones y logros; y (3) ejercitar principios y lormas de solidaridad entre diferentes movimientos sociales significativos de distintos países o bloques.

(f) La existencia de las premisas para la realización del commismo. Marx dice que si las condiciones no se dan, el capitalismo y el mercado "quedarán como 《<ircunstancias〉 provocadoras de supersticiones locales". También dice que la profundización y ampliación del mercado mundial "aboliría el comunismo local". Lo que hemos observado en el último siglo y medio son avances de la clase trabajadora en los estados capitalistas y revoluciones anticapitalistas, que fueron repetidamente distorsionadas, neutralizadas y/o deslegitimadas por la dinámica del crecimiento del capital internacional. En otras palabras, lo que hemos presenciado han sido movimientos revolucionarios de la clase trabajadora y revoluciones nacionales contra el capitalismo, pero sin llegar a superarlo.

\section{El comunismo como movimiento político internacional}

Veamos ahora el Manifiesto Comunista. Ciertamente la parte más recordada son sus palabras finales: "iProletarios de todos los países, uníosi” En esta frase se sintetiza el internacionalismo proletario que el Manifiesto quiere fundamentar, y es lo que ha determinado el atractivo del Manifiesto como un todo. Dada la extensión del texto, no podemos extraer un párrafo significativo para analizarlo, como hicimos con la Ideología Alemana. Sin embargo, podemos extraer tres elementos principales para propósitos de análisis y discusión.

(a) La internacionalización de la burguesía como acontecimiento progresista. En el texto, Marx y Engels consideran a la burguesía en ascenso como progresista, en virtud de su papel modernizador, homogeneizador y unificador del mundo. La extinción con la cual el desarrollo de la burguesfa amenaza a las naciones bárbaras y semibárbaras se presenta como "civilización". "La burguesia, con su dominio de clase, que cuenta apenas con un siglo de existencia, ha 
creado fuerzas productivas más abundantes y más grandiosas que todas las generaciones pasadas juntas. El sometimiento de las fuerzas de la naturaleza, el empleo de las máquinas, la aplicación de la química a la industria y a la agricultura, la navegación de vapor, el ferrocarril, el telégrafo eléctrico, la adaptación para el cultivo de continentes enteros, la apertura de ríos a la navegación, poblaciones enteras surgiendo de la tierta como por encanto. ¿Cuál de los siglos pasados pudo sospechar siquiera que semejantes luerzas productivas dormitasen en el seno del trabajo social?". A la luz de lo ocurrido en el último siglo y medio, es necesario criticar este cuadro. No es necesario mencionar el vínculo que estas expresiones tienen con la burguesía europea más chauvinista y racista que se expresa en la actualidad. Lo que sí es necesario asentar es que la industrialización e internacionalización capitalista ha sido, en cualquier caso, un fenómeno altamente contradictorio que si bien, por un lado, ha desarrollado las fuerzas productivas hasla grados insospechados, por otro ha provocado una dinámica deshumanizante y alienante para los seres humanos y, a la vez, destructiva del medio ambiente.

(b) El prolesariado como sujeto de la liberación mundial. El proletariado es dotado por el Manifiesto con cualidades positivas y universales. Es libre de cualquier carácter nacional y de los prejuicios de la burguesía. "De todas las clases que hoy se enfrentan con la burguesía sólo el proletariado es una clase verdaderamente revolucionaria (...). Los proletarios no pueden conquistar las fuerzas produclivas sociales, sino aboliendo su propio modo de apropiación en vigor, y, por tanto. todo modo de apropiación existente hasta nuestros días. Los proletarios no tienen nada que salvaguardar; tienen que destruir todo lo que hasta ahora ha venido garantizando y asegurando la propiedad privada existente". Y en otra parte, dice: "Los trabajadores no tienen país, ellos no tienen nada que perder, excepto sus cadenas". El argumento es claro: desde el momento que el proletariado es libre de la burguesía y de sus prejuicios nacionalistas, desde que es libre de cualquier atadura en la sociedad existente, puede, por tanto, poner lín a los conflictos entre las naciones, lo que requerirá, primero, que tome el poder del estado-nación al derrocar a las viejas clases gobernantes que son responsables de los conllictos internacionales. Considerando este punto de vista, es necesario hacer algunas observaciones.

Primero, las características positivas, progresistas y prometeicas que son asignadas a la clase trabajadora tienen poca o ninguna correspondencia con las características del proletariado británico de las primeras décadas del siglo XIX, que fue descrito por Engels unos pocos años antes de la redacción del Manifiesto. En sus últimos escritos sobre la clase trabajadora británica, sobre sus líderes y organizaciones, Marx y Engels observaron su identificación nacionalista, su chauvinismo y subordinación a las ideas de la burguesía y sus instituciones. 
Segundo, el argumento es clasista-reduccionista al sugerir que el estado y la nación son únicamente formas de existencia, o expresiones de clases, y también al determinar la opresión social y la liberación. Parecería hoy superfluo tener que resaltar el continuo, y a menudo creciente, peso del estado y la nacionalidad/etnicidad en la determinación de las relaciones entre los pueblos. Las relaciones, algunas veces violentas y ordinariamente tensas, entre los Estados comunistas o ex comunistas y la discriminación estatal permanente, en el interior de ellos, contra minorias religiosas o étnicas, pone en evidencia el peso de estos factores. En la medida que los reglmenes comunistas han desaparecido, la etnicidad ha aparecido como su principal heredero.

Tercero, el argumento es evolucionista al sugerir que el proletariado tiene que completar la tarea iniciada por la burguesía en lugar de criticar y transformar todas las relaciones burguesas y sus procesos.

Cuarto, el argumento es etapista al sugerir que la lucha nacional de alguna manera precede a la lucha internacional, o que los conflictos internacionales no pueden ser resueltos sin el dominio proletario en el ámbito nacional. Esto supone una prioridad de las luchas, o un orden separado de niveles, que contradice lo expresado en el texto de la Ideología Alemana y una visión dialéctica de las relaciones entre las esferas nacional e internacional, en la que se da una codeterminación entre ambas.

En resumen, dada la naturaleza compleja del proletariado de los siglos XIX y $\mathrm{XX}$, dada la complejidad de las estructuras sociales en las cuales existió y existe dicho proletariado, el retrato de un proletariado liberado y liberador, sujeto y vanguardia internacionalista, es simplemente "un ideal" hacia el cual la realidad debe de ajustarse; algo, simplemente, que no ha tenido referencia empírica e histórica ni la tendrá.

(c) El papel de los comunistas. El Manifiesto lo expresa así: "Los comunistas sólo se distinguen de los demás partidos proletarios en que, por una parte, en las diferentes luchas nacionales de los proletarios destacan y hacen valer los intereses comunes a todo el proletariado, independientemente de la nacionalidad; $y$, por otra pare, en que, en las diferentes fases de desarrollo por que pasa la lucha entre el proletariado y la burguesía, representan siempre los intereses del movimiento en su conjunto". La aspiración expresada por Marx y Engels en la afirmación anterior ha sido desvirtuada por el comportamiento histórico del ex bloque de países socialistas y el de los partidos comunistas y movimientos revolucionarios de orientación socialista. No podemos observar ahora, incluso en aquellas tradiciones internacionalistas heterodoxas, como la trotskysta y la anarcosindicalista, el embrión de una organización que no sólo sea internacionalista sino que, además, posea las caracterlsticas requeridas por el Manifiesto: que no sea opuesta a los otros partidos de la clase trabajadora, que no se separe del proletariado y que no posea principios sectarios. 
Es curioso que el Manifiesto, el más político y estratégico de los dos textos, parece ser menos documentado y menos relevante que los escritos anteriores de Marx y Engels, más abstractos y más filosóficos. Esto sugiere que debemos liberarnos del proyecto de internacionalismo de la política del siglo XIX, dominada por el mercado, la industrialización, el conflicto trabajo- capital, nación y construcción imperial y la lucha exclusiva por el control de la maquinaria del estado, como modelo único de liberación y emancipación humana.

Dada las características del actual orden mundial, debemos utilizar la imaginación para superar el viejo concepto de internacionalismo y diseñar un nuevo internacionalismo de orientación global y a los problemas globales, más que a los problemas internacionales. Promover un movimiento democrático-radical para la solidaridad global. 